\title{
Calatrava La Vieja (Carrión de Calatrava, Ciudad Real) en las postrimerías de la Edad del Bronce (ca. 1200-800 a.C.) ${ }^{1}$
}

\section{Calatrava la Vieja (Carrión de Calatrava, Ciudad Real) in the Late Bronze Age (c. 1200-750 BC)}

\author{
Pedro Miguel Naranjo \\ Universidad de Castilla-La Mancha \\ Pedro.Mnaranjo@uclm.es
}

Fecha de recepción: 14-06-2019

Fecha de aceptación: 16-07-2019

\section{RESUMEN}

Las campañas arqueológicas llevadas a cabo en Calatrava la Vieja desde 1984 han sacado a la luz materiales de época protohistórica que revelan fases de ocupación previas a la fundación de la ciudad andalusí en el siglo VIII d. C. Entre los materiales exhumados se han seleccionado las cerámicas del Bronce Final, situadas cronológicamente en función de la posición estratigráfica de estos materiales en los yacimientos circundantes. Esta etapa es, según la documentación disponible, la más antigua del yacimiento hasta la actualidad. Las formas registradas revelan una amplia red de contactos con otros ámbitos peninsulares en los que Calatrava jugó un papel destacado en el contexto del Alto Guadiana.

Palabras clave: Cerámica, contactos culturales, Meseta Suroriental, Calatrava la Vieja Topónimos: Ciudad Real, España

Período: Bronce Final

\section{ABSTRACT}

The archaeological works undertaken in Calatrava la Vieja since 1984 have revealed protohistorical materials which demonstrate that this archaeological site was occupied before the foundation of the Islamic city in the VIII century A.D. From among the materials discovered, I have selected the ceramics from the Late Bronze Age. These ceramics have been dated following comparison with the different ceramic typologies found in nearby archaeological sites. This phase is, according to

1 Este trabajo se ha podido realizar gracias a la concesión de un contrato predoctoral del plan propio de la Universidad de Castilla-La Mancha. También quería agradecer a los directores del yacimiento de Calatrava la Vieja, D. Manuel Retuerce Velasco (Universidad Complutense de Madrid) y D. Miguel Ángel Hervás, el acceso a las piezas estudiadas en este trabajo. 
available documentation, the oldest found on the site so far. The pottery reveals a wide network of contacts between Calatrava la Vieja and other peninsular areas in which Calatrava played prominent role in the context of Alto Guadiana.

Key words: Pottery, cultural contacts, Southeast Plateau, Calatrava la Vieja

Place names: Ciudad Real, Spain

Period: Late Bronze Age.

\section{INTRODUCCIÓN}

El yacimiento de Calatrava la Vieja (Carrión de Calatrava, Ciudad Real) se localiza sobre una elevación amesetada de entre los 5 y $10 \mathrm{~m}$. con respecto al nivel del espacio circundante (630 m. sobre el nivel del mar), posición que le permitió un amplio dominio visual en un espacio de extensa llanura (figs. 1, 2). Ello, unido a su posición junto a las vegas del río Guadiana, favoreció el desarrollo de una agricultura floreciente que debió de complementarse con otro tipo de actividades económicas como la ganadería, la artesanía, la metalurgia o el comercio (Retuerce, 1994: 217-218).

Figura 1. Foto aérea del yacimiento de Calatrava la Vieja (Carrión de Calatrava, Ciudad Real).

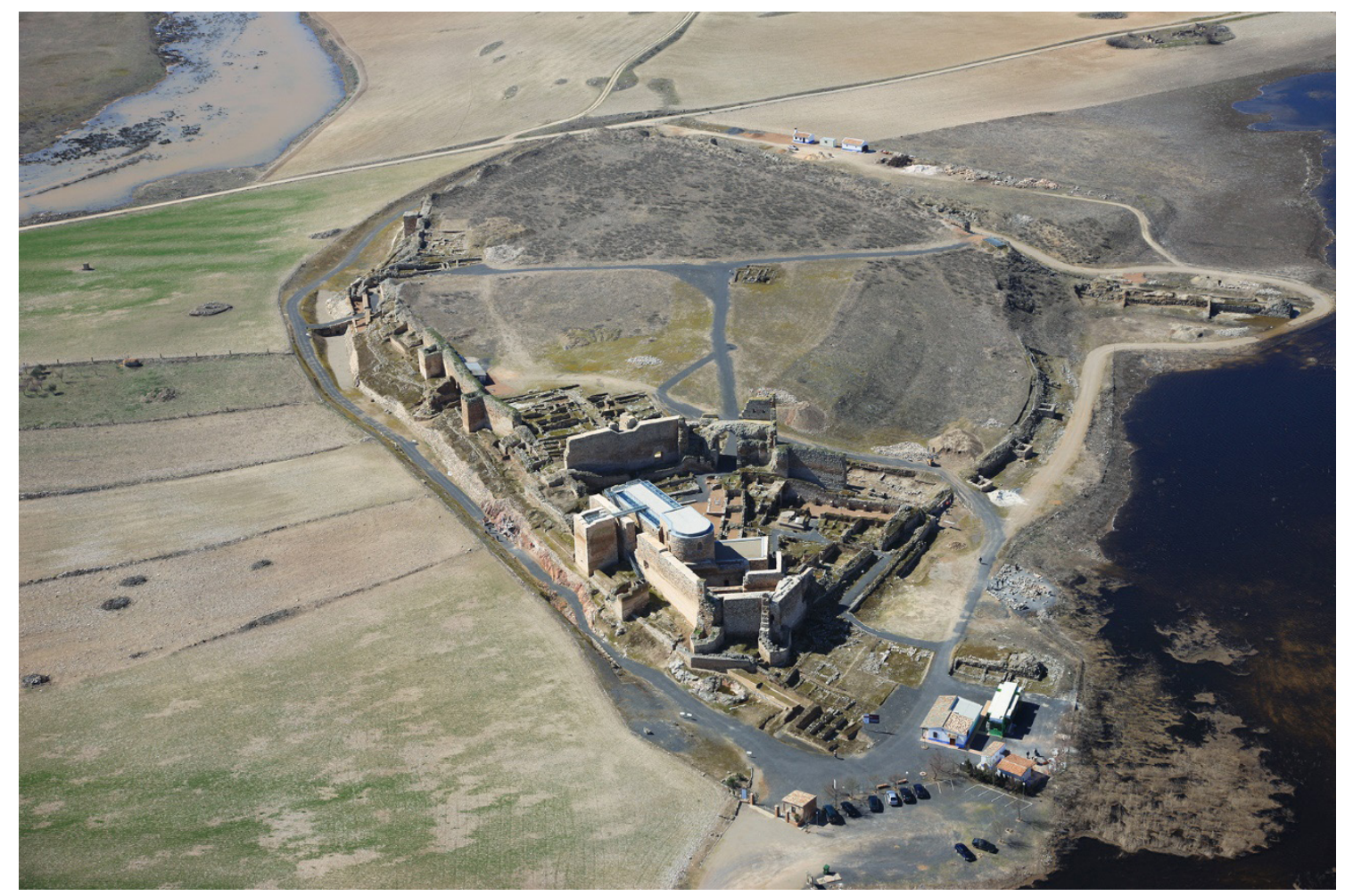

Fuente: Miguel Ángel Hervás Herrera y Manuel Retuerce Velasco. Archivo de Calatrava la Vieja.

La presencia de fases de ocupación previas a época altomedieval en Calatrava la Vieja ha sido recientemente valorada a partir de materiales arqueológicos fuera de contexto, concretamente formando parte de tapiales o basureros medievales (Blanco, Hervás y Retuerce, 2012; Miguel, 2014; 2017; 2019). Entre estos materiales figuran mayoritariamente los de época íbera, intuyéndose desde hace tiempo la existencia de un oppidum ibérico de aproximadamente 6 ha. según se desprende de algunos retazos de la muralla íbera 
detectados (Retuerce, 1994: 218; Retuerce y Hervás, 2004: 391). También se constataron dos hornos de pan ibéricos (García Huerta, Morales, Vélez, Soria, y Rodríguez González, 2006: 159-160, fig. 2), las únicas estructuras protohistóricas in situ documentadas hasta la actualidad.

Aparte, y siendo objeto de estudio en el presente trabajo, existen evidencias arqueológicas que atestiguan unas fases anteriores a la segunda Edad del Hierro y que, muy probablemente, constituyeron los prolegómenos de la configuración del oppidum oretano. Estos primeros pasos se sitúan cronológicamente en el Bronce Final, periodo más antiguo hasta ahora constatado en este yacimiento. Dichas fases ya fueron definidas en un trabajo de Blanco, Hervás y Retuerce (2012), aunque se trata de una aportación muy general en la que no se concretaron formas, vías de contacto y otros aspectos de interés que pueden extraerse del estudio de la cultura material.

Los materiales objeto de estudio en el presente artículo, exclusivamente cerámicos, también proceden de depósitos secundarios, concretamente basureros y tapiales medievales (fig. 2). Las cerámicas exhumadas proceden de las excavaciones que anualmente se han venido desarrollando en Calatrava la Vieja desde 1984 hasta la actualidad, por lo que se trata de todos los testimonios relativos a dichas fases que se conocen hasta la fecha. De todo el conjunto se han seleccionado únicamente las cerámicas del Bronce Final, realizadas a mano y con unas características técnicas y morfológicas típicas de este momento.

Figura 2. Áreas de procedencia de los materiales estudiados

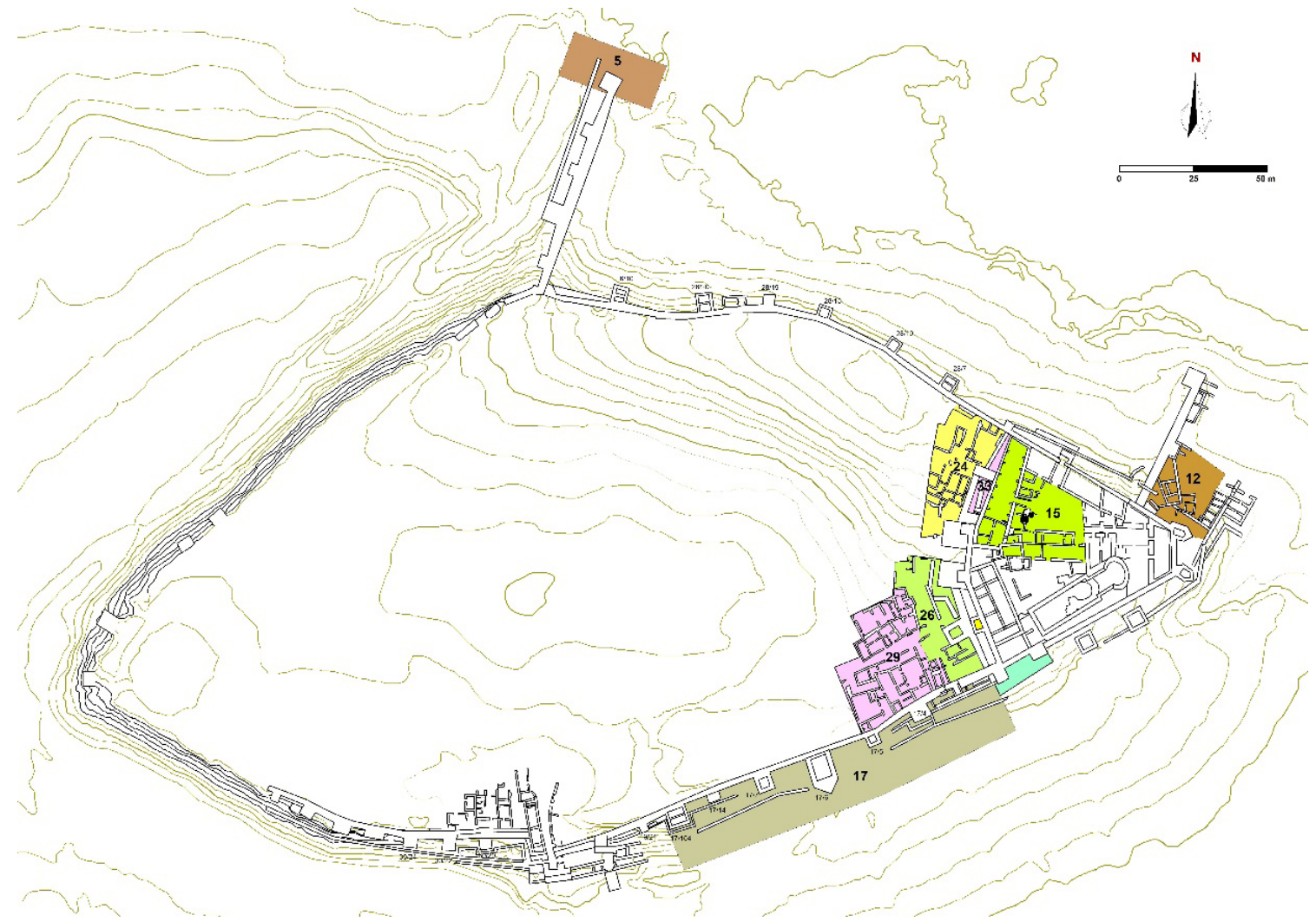

Fuente: Miguel Ángel Hervás Herrera y Manuel Retuerce Velasco. Archivo de Calatrava la Vieja.

En cuanto a la metodología, y siempre a expensas de la fragmentación de las piezas, se ha procedido a un análisis macroscópico que ha permitido identificar diferentes formas y grupos. Del material estudiado se deduce una gran calidad en la práctica totalidad de las piezas, una calidad que queda reflejada en las pastas depuradas de granulometría media- 
fina, cocciones regulares (generalmente reductoras) y ambas superficies someramente bruñidas. Ello permite concluir la existencia mayoritaria de una vajilla fina de gran calidad con algunas formas de acceso restringido.

Las características morfológicas de cada pieza se han relacionado con los yacimientos que han proporcionado un material afín en contextos estratificados, muchos relativamente lejanos a Calatrava la Vieja ya que algunas de las formas o decoraciones constatadas tienen su origen en otras culturas peninsulares de esta fase. En la medida en que los materiales lo han permitido, se han considerado especialmente los paralelos en los yacimientos aledaños con el fin de ajustarse a la realidad circundante de la Meseta suroriental. Para la clasificación de algunas de las formas típicas del Bajo Guadalquivir se ha utilizado la tipología de Ruiz Mata (1995), bastante útil y precisa en términos morfológicos. Sin embargo, el factor cronológico que lleva implícito ha sido criticado por algunos investigadores (Belén, 2001: 46; Casado, 2015: 179). Por este motivo, las consideraciones cronológicas de dicha tipología serán cotejadas con las fechas radiocarbónicas que se han obtenido de aquellos contextos en los que se han hallado paralelos.

Pese a ello, y a la espera de hallar niveles in situ relativos a esta época, serán las futuras excavaciones y cronologías radiocarbónicas asociadas a materiales en posición primaria las que verifiquen o no lo apuntado en estas líneas. Hasta entonces, solo nos valemos de este tipo de estudios para una aproximación a esta fase tan desconocida en la Meseta sur en general y en Calatrava la Vieja en particular. De hecho, en la actualidad no se conoce ningún yacimiento con niveles del Bronce Final en el Alto Guadiana, ya que los niveles más antiguos registrados en los oppida de este contexto, como Alarcos, La Bienvenida-Sisapo o el Cerro de las Cabezas, remiten al periodo transicional Bronce Final-Hierro I.

De esta forma, el panorama cronológico y cultural del Alto Guadiana durante el Bronce Final se ha esbozado a partir de los escasos y exclusivos materiales fuera de contexto, como las estelas del Suroeste o algunos materiales de prospección. La dificultad para perfilar estos momentos ha venido determinada, en parte, por la existencia de un hiatus entre el Bronce Medio y el Bronce Final que algunos autores, como Almagro Gorbea (1999: 29), han intentado solventar con la perduración de un sustrato local del Bronce Medio. Sin embargo, varios investigadores se han opuesto a estas teorías que buscan cubrir un lapso temporal de escasa evidencia arqueológica (Pérez Avilés y Vélez, 1996: 14; Morales, 2010: 92).

Este déficit de información sobre el Bronce Final en la Meseta suroriental no sólo ha de ponerse en relación con algunas de las características que marcan el patrón de asentamiento durante estos contextos, sino también con la falta de excavaciones sistemáticas. Por todo ello, la información que ofrece Calatrava la Vieja supone una aportación destacada para la reconstrucción de una de las etapas más oscuras del Alto Guadiana, situación extensible a otras áreas peninsulares como el Bajo Guadalquivir (Escacena, 1995) o el Guadiana Medio (Celestino y Rodríguez González, 2017: 183-212; Rodríguez González, 2018: 51-67).

\section{ESTUDIO DE LOS MATERIALES: LAS FORMAS}

\subsection{Recipiente con cuello troncocónico}

Dentro las cerámicas de tradición de Cogotas I (fig. 4:1-5) destaca un recipiente de cuello troncocónico, de pasta depurada y desgrasantes de cuarzo y mica (fig. 4:2). Presenta paralelos en Las Roturas II, donde se vinculó a momentos avanzados de la Edad del Bronce y previos a las influencias de Campos de Urnas en la Meseta Norte (Sesma, Bienes, Herce, Faro y Ramos, 2009: 57-59 fig. 16:4). Tanto la decoración como la forma fueron halladas en Fuente Álamo (Abarquero, 2005: fig. 65:2) en un ambiente cultural de Cogotas I, elemento definitorio del Bronce Final en la Meseta Suroriental como así se ha valorado para los ejemplares hallados en Alarcos (García Huerta y Fernández Rodríguez, 2000: fig. 4), Plaza 
de los Moros (Malagón) (Blasco, 1986: 360) o Los Amelgares (Zarzalejos, Esteban y Hevia, 2012: 17-18).

\subsection{Vasos cerrados de borde apuntado}

Esta forma queda atestiguada por tres fragmentos bastante homogéneos en su factura de gran calidad (figs. 2:3-4). Probablemente pertenecieron a la vajilla fina de lujo, con diámetros entre los 14 y $18 \mathrm{~cm}$. y grosores de entre los 5 y $7 \mathrm{~mm}$. Su alto valor queda corroborado por la decoración impresa e incisa en uno de los fragmentos (fig. 4:3), desarrollándose un motivo típico de la fase Protocogotas (Fernández Posse, 1982: figs. 2:1,6,9,11,14; 3:2-5; Pellicer, 1987-88: fig. 9:1; Ruiz Zapatero, 2007: fig. 4c). La fragmentación de los ejemplares no ha permitido reconstruir la forma, aunque parece tratarse del típico vaso de cuerpo elipsoide y borde recto-apuntado de Protocogotas (Abarquero, 2005: 2930, fig. 3: 7), decorado frecuentemente en la superficie interna con el ribeteado en zigzag al igual que el fragmento de Calatrava.

\subsection{Cazuela de bordes rectos y perfil trapezoidal}

Se trata de una forma que sólo queda representada por un ejemplar de $32 \mathrm{~cm}$. de diámetro y ambas superficies bruñidas (fig. 4:5). Este tipo no se ha registrado en ningún otro yacimiento del Alto Guadiana, aunque sí en otras áreas más alejadas como Fuente Álamo (Cuevas de Almanzora, Almería) (Abarquero, 2005: 175-176, fig. 65:6), el Castillo de Alange (Abarquero, 2005: 159-160, fig. 53: 5), Cuesta del Negro (Abarquero, 2005: fig. 71: 13) o El Canjorro (Jaén) (Abarquero, 2005: fig. 76: 2). Todos estos casos remiten a contextos de Protocogotas que se han fechado entre el 1300 y el 1200 a. C. Por tanto, y en conexión con este círculo cultural, esta cazuela, así como el resto de formas de filiación cogoteña, se fecharía en torno al 1200 a.C.

\subsection{Cazuelas de carena alta del tipo A.I.a de Ruiz Mata}

Este tipo de cazuelas, de fondos planos, cuerpo hemisférico, cocciones reductoras y superficies esmeradamente bruñidas, presenta una acusada carena externa como elemento más definitorio. La configuración del borde, de sección almendrada, determinó variedades regionales. En Calatrava la Vieja se han registrado dos cazuelas de carena alta muy marcada (fig. 4:6-7), aunque solo una de ellas presenta unas características que permiten precisar una cronología relativa (fig. 4:5). Este ejemplar, de $21 \mathrm{~cm}$. de diámetro y una perforación bajo la carena para su probable suspensión, corresponde con la cazuela A.I.a de la variante Guadalquivir de Ruz Mata (1995: 267-268), la forma A’16 de López Roa (1977: 362), forma 6C de González de Canales, Serrano y Lompart (2010: fig. 14) o una de las formas recogidas en el grupo I-b.1 de Casado (2015: fig. 131:2, 3, 5). Dentro de la sistematización de Murillo (1994: fig. 5.29), oscilaría entre la forma B1.1/D2C y B1.1/D2D.

Las cazuelas A.I.a con esta morfología, que en este caso muestra dos círculos incisos en la superficie interna del labio, son muy frecuentes en la Baja Andalucía. Así lo constatan Ios materiales de El Carambolo (Carriazo, 1973: 382; López Roa, 1977: fig. 8), la Fase I del Cabezo de San Pedro (Blázquez, Ruiz, Remesal, Ramírez y Clauss, 1979: 177; Ruiz, Blázquez y Martín de la Cruz, 1981: 230-257), el Cerro del Casar (Ruiz Mata, 1995: fig. 4: 1), el Puerto del Barco (Ruiz Mata, 1995: fig. 4:4), el Jardín de Alá, (Hunt y García Rivero, 2017: fig. 33:JA-804) o la Cuesta de los Cipreses (Ferrer, Ruiz y García, 2017: fig. 17:5-6). En las últimas intervenciones de El Carambolo también se ha exhumado una cazuela de este tipo, adscrita a la Fase III (Fernández Flores y Rodríguez Azogue, 2007: 154, fig. 54: CAR-15-94), aunque las recientes interpretaciones integran el ejemplar en una fase más antigua (Torres, 2016: 80-86). 
En el Valle Medio del Guadalquivir también aparecen este tipo de recipientes, concretamente en la fase B del fondo 8 de Vega de Santa Lucía (Murillo, 1994: figs. 4.31: 388; 4.37: 559), en el fondo 4 de este mismo yacimiento (Murillo, 1994: 127-131, fig. 4.52: 4) o en los niveles del Bronce Final del Llanete de los Moros (Córdoba) (Martín de la Cruz, 1987: 205-206, figs. 26: 165, 43: 535). Para algunos de estos contextos contamos con fechas radiocarbónicas calibradas, como la fase B de Vega se Santa Lucía (Tab. 1), que remiten al siglo IX cal. a.C.

La cronología absoluta de las cazuelas del tipo A.I.a se sitúa entre los siglos IX-VIII a. C. (Pellicer, 1987-88: 466, fig. 5:12; Ruiz Mata, 1995: 267; 2014: 5), consideración avalada por los estilos decorativos a los que aparece frecuentemente asociada, como la decoración bruñida interna (López Roa, 1977: 341-370; Ferrer, Ruiz y García, 2017: fig. 17:5-6) o pintada al estilo Carambolo (Ruiz Mata, 1984-85: fig. 1.1; 2014: 8; Mederos, 2017).

Aunque no es la variante Guadalquivir, sino del tipo onubense, los datos de La Bienvenida revelan la presencia de una cazuela A.I.a en el estrato 13 (Fernández Ochoa, Zarzalejos, Hevia y Esteban, 1994: fig. 122), fechado a finales VIII o principios del VII a. C. por el hallazgo de copas de paredes finas pintadas al estilo San Pedro II (Zarzalejos y López Precioso, 2005: 815) en un contexto de total ausencia de cerámica a torno (Zarzalejos, Fernández y Hevia, 2004: 166; Zarzalejos y López Precioso, 2005: 815; Zarzalejos, Esteban y Hevia, 2012: 28-31; Zarzalejos, Fernández, Esteban y Hevia, 2015: 46-47), ausencia que no implica necesariamente un ambiente prefenicio (Belén, 2001: 38). Sin embargo, ya se planteó la necesidad de retrotraer la cronología del estrato 13 de La Bienvenida, como mínimo, hasta mediados del siglo VIII a.C. (Miguel, 2019: 92), por lo que sus materiales, incluida la cazuela A.I.a del tipo onubense, se fecharían en el 750 a.C. o antes.

En Alarcos, las cazuelas A.I.a aparecen estratificadas en niveles cuyas dataciones radiocarbónicas se sitúan entre los siglos IX-VIII cal. a.C. (García Huerta y Morales, 2017: Tab. 1, fig. 12:4), mientras que en el Cerro de Las Cabezas se hallan bajo un contexto del Bronce Final-Hierro I en el que se han reconocido influencias de la Baja Andalucía (Vélez y Pérez 1987: 173-174, lám. I: 7, lám. II: 21; 1994:136-138; 1999: 51; Esteban, Hevia, Pérez y Vélez, 2003: 20, fig. 6:10). Dichas influencias se han estimado antes de las primeras evidencias del mundo colonial (Vélez y Pérez 1999: 52-53; Esteban, Hevia, Pérez y Vélez, 2003: 26). Sin embargo, la cronología radiocarbónica de la presencia estable fenicia en la península ibérica se ha estimado en el 825 cal. a.C. (Torres, 2008: 140), por lo que en este periodo el sur de la península ibérica estaba inserto en el ambiente cronológico y cultural de la Primera Edad del Hierro. En todo caso, como revela el contexto cultural de Alarcos y La Bienvenida-Sisapo, la cazuela A.I.a perduraría durante la transición del Bronce Final a la Primera Edad del Hierro.

De este modo, y analizadas las estratigrafías en las que se documentan las cazuelas del tipo A.I.a de la variante Guadalquivir, lo más prudente sería situar el fragmento de Calatrava la Vieja en un lapso temporal que abarca desde principios del siglo IX hasta mediados del VIII a. C. Dicha cronología se mostraría acorde con los datos que han proporcionado los yacimientos reseñados, así como las dataciones radiocarbónicas referidas. Por tanto, según esta consideración cronológica, esta forma típica del Bronce Final pudo incluirse en un contexto transicional Bronce Final-Hierro I como revela su asociación a las cerámicas San Pedro II.

Por otro lado, parece que la forma A.I.a de la variante Guadalquivir se desarrolló en Calatrava la Vieja gracias a los contactos culturales que se desarrollaron entre la Baja Andalucía y la submeseta sur, patentes en algunos testimonios como la cerámica estilo Carambolo de Alarcos (García Huerta y Fernández Rodríguez, 2000: fig. 5:2). Es posible que dichos contactos se establecieran surcando el curso del Guadalquivir de ahí la afinidad con los materiales de Vega de Santa Lucía o el Llanete de los Moros. 


\subsection{Cazuelas A.I.b de Ruiz Mata}

La otra cazuela registrada en Calatrava la Vieja (fig. 4:8), de $20 \mathrm{~cm}$. de diámetro, se emparenta con el tipo A.I.b de Ruiz Mata (1995: 268, fig. 6: 4 y 5) o la forma C3 de González de Canales, Serrano y Lompart (2010: fig. 14), caracterizada fundamentalmente por una amplia carena que determina un largo tramo de escalón. Por lo demás, sigue la tónica de las cazuelas anteriores en cuanto a los fondos planos y los cuerpos de casquete esférico.

La forma A.I.b es muy común en el área onubense, como en la Fase I del Cabezo de San Pedro (Blázquez, Ruiz, Remesal, Ramírez y Clauss, 1979: 32-55, figs. 18:53, 19:5759, 24:128), aunque no faltan algunos ejemplares en el Valle del Guadalquivir (Ruiz Mata, 1995: 268) como en la Cuesta de los Cipreses (Ferrer, Ruiz y García, 2017: figs. 8:7, 13:4, 5) o el Llanete de los Moros (Martín de la Cruz, 1987: 206, figs. 37:381, 388). También se han documentado en el nivel VII del yacimiento de San Pablo (Málaga) que se ha fechado en el siglo VIII a. C. (García Alfonso, 2007: 84, fig. 184). Este tipo de cazuela también suele ostentar la rica decoración al estilo Carambolo (Ruiz Mata, 2014: 1-11), de ahí que se hayan datado durante el siglo IX y la primera mitad del siglo VIII a.C. (Pellicer, 1987-88: 466, fig. 5:10; Ruiz Mata, 1995: 281; Torres, 2002: 134).

Actualmente no se cuenta con cazuelas A.I.b en el Alto Guadiana que permita una mayor precisión, salvo los ejemplares de Casa de Rana que se hallaron en superficie (Zarzalejos, Esteban y Hevia, 2012: 34, fig. 15: 40). Por tanto, y teniendo en cuenta la posición que ocupan en los yacimientos de la mitad sur peninsular, así como el desarrollo coetáneo de las cazuelas A.I.a y A.I.b (Ruiz Mata, 1995: 267-268), se propone para la cazuela A.I.b de Calatrava la Vieja un lapso temporal que abarca desde principios del siglo IX a mediados del siglo VIII a.C.

\subsection{Vasos bicónicos o A.I.f de Ruiz Mata}

Se trata de un vaso cerrado de perfil bicónico, con una carena en su parte media que separa una mitad inferior semiesférica y otra superior troncocónica. El borde es corto, vertical o ligeramente exvasado. Fue una forma muy recurrente en el Bajo Guadalquivir durante el Bronce Final y la Primera Edad del Hierro (Pellicer, 1987-88: 465-466, fig. 7:5; Ruiz Mata 1995: 268-269, fig. 9; 2014: 5; Brandherm y Krueger, 2017: 307-308, 311), decorándose en ocasiones con los típicos motivos de la cerámica estilo Carambolo (Ruiz Mata, 1984-85: fig. 3; Casado 2015: 138, fig. 86:DJ/2002/24/12-142). En cuanto a su función, los vasos bicónicos se utilizaron como urnas cinerarias o elementos de ajuar (Torres, 1996: fig. 1:1-2; Brandherm y Krueger, 2017: 296-318).

Todos los vasos bicónicos de Calatrava la Vieja se caracterizan por presentar una gran calidad, perceptible en las cocciones homogéneas (oxidantes o reductoras), las pastas depuradas y el sobresaliente bruñido de ambas superficies (generalmente negras). Son de grandes dimensiones, con diámetros que oscilan entre los 14 y los $22 \mathrm{~cm}$. En la configuración de los bordes se aprecian pequeñas variaciones, diferenciándose entre aquellos que presentan un estrangulamiento exterior acusado (fig. 4:9-10) y otros con una mayor continuidad en la dirección del galbo, aspecto que les concedió una mayor profundidad (fig. 4:11-12).

Los paralelos más afines, concretamente la variante de borde diferenciado, se localizan en Valencina de la Concepción (Ruiz Mata,1995: fig. 9), Mesas de Asta (Ruiz Mata, 2014: 3) y la Universidad Laboral (Fernández Gómez y Buero, 2010: 81-82), estos últimos fechados entre el siglo X y el VIII a. C. según la cronología convencional.

En cuanto a la datación radiocarbónica, la muestra de vida corta del fondo J del Jardín de Alá, donde se halló un vaso bicónico del tipo A.I.f (Hunt y García Rivero, 2017: fig. 33: JA- 
791) y una cazuela A.I.a de la variante Guadalquivir (Hunt y García Rivero, 2017: fig. 33:JA804), ofrece una cronología del siglo IX cal. a. C. Dicha consideración sería extensible al vaso bicónico del santuario de El Carambolo (Fernández Flores y Rodríguez Azogue, 2007: fig. 15: CAR-2619-6) según se desprende de la muestra de carbón hallada en los niveles fundacionales (Tabla 1). La publicación de las fechas absolutas de la necrópolis de Setefilla también corroboran la inclusión de esta forma en el Bronce Final, ya que sitúan el vaso bicónico entre el 1217 y finales del siglo IX cal. a.C. (Brandherm y Krueger, 2017: 307-311).

En el Guadalquivir Medio están presentes tanto los vasos bicónicos de borde diferenciado como aquellos con una mayor verticalidad en el borde, ambos tipos con una cronología que se centra en el siglo IX cal. a. C., como en Vega de Santa Lucía (Murillo, 1994: figs. 4.9:26; 4.10:50; 4.11:81-85, 4.15:143; 4.25; 4.32; 4.42:666; 4.49; 4.7:20). Otros yacimientos del entorno también remiten al Bronce Final, como La Saetilla (Murillo, 1994: 4.71:1676; 4.73:1098; 4.76:709, 710, 731) o el estrato II del Llanete de los Moros (Martín de la Cruz, 1987: fig. 20: 94).

En el Alto Guadiana sólo se ha documentado el vaso bicónico de la necrópolis del sector IV-E de Alarcos (García Huerta y Fernández Rodríguez, 2000: fig. 9:1; Fernández Rodríguez, 2001: fig. 4:1), utilizado como urna cineraria y fechado a finales del siglo VII o principios del VI a. C. según los paralelos con el túmulo B de Setefilla (Fernández Rodríguez, 2001: 265, 275; 2012: 55). No obstante, hubo investigadores que dataron el vaso bicónico de Alarcos antes del 700 a. C. (Torres 2002: 135-137), consideración que queda corroborada por las recientes dataciones absolutas de Setefilla (Brandherm y Krueger, 2017). Además, este ejemplar está decorado con incrustaciones metálicas, un recurso que ha sido fechado entre los siglos X y VIII a. C. (Murillo 1994: 328; Torres 2001: 275-281; 2002: 136).

Todos los paralelos apuntados permiten situar los vasos bicónicos de Calatrava la Vieja en el siglo IX cal. a. C., aunque la cronología tradicional extiende el límite inferior hasta el 750 a. C. Dicha forma halla sus paralelos más cercanos en el valle del Guadalquivir, probablemente la zona en la que se desarrolló este vaso durante el Bronce Final y cuya presencia en Calatrava la Vieja se deba a los intensos contactos entre ambas regiones durante este periodo.

\subsection{Soportes de carrete}

Una de las piezas conservadas presenta un extremo apuntado que se engrosa progresivamente para luego ir reduciendo las dimensiones de sus paredes conforme se desarrolla la forma (fig. 4:13). El recipiente, de $22 \mathrm{~cm}$. de diámetro y superficies bruñidas, presenta las típicas características morfológicas de los soportes de carrete, aunque el estado fragmentario de la pieza no permite saber si presentó baquetón (Pellicer, 1987-88: 467 figs. 1:16; 5: 14, 16; 6: 2; 7: 2 y 3; Ruiz Mata, 1995: 269-270). Sin embargo, la forma apuntada con la que se remata este fragmento recuerda bastante a esta forma denominada D.I por Ruiz Mata (1995: fig. 10). La pieza presenta paralelismos con los ejemplares de la Saetilla (Murillo, 1994: fig. 4.73:1102), Los Concejiles (Vilaça, Jiménez y Galán, 2012: fig. 7), el fondo 3 de Peñalosa (García Sanz y Fernández Jurado, 2000: lám. 27:2) o el del Cabezo de San Pedro (Ruiz Mata, 1995: fig. 10:3), todos ellos fechados entre los siglos IXVIII a.C. según la cronología tradicional.

En la provincia de Ciudad Real se constató un ejemplar de este tipo en La Pizarrilla (Cózar), una pieza descontextualizada que se situó en el Bronce Final (Pérez Avilés, 1985: 195, fig. 5). En Alarcos se ha registrado un soporte de carrete del tipo D.Il de Ruiz Mata (1995: fig. 10), fechado por C-14 en la primera mitad del siglo VIII cal. a.C. (García Huerta, e.p.: cuadro 1). Esta forma es muy típica del mundo tartésico (Ruiz Mata 1995: 269-270, fig. 10), aunque también se documenta en el horizonte de Cogotas I como consecuencia de los 
contactos entre la Meseta y la Baja Andalucía (Blasco y Lucas, 2001: 225-226, fig. 4:7). En cuanto a su función, hay autores que han señalado su utilidad como verdaderos soportes de todas aquellas formas abiertas de base convexa típicas de la época, como las cazuelas A.I.a o A.I.b (Torres, 2002: 135).

Atendiendo a los recientes datos de Alarcos, y especialmente a la muestra de vida corta sometida a C-14 (García Huerta, 2019: cuadro 1), el soporte de Calatrava se fecharía en la primera mitad del siglo VIII cal. a.C.

Tabla 1. Dataciones radiocarbónicas mencionadas en el texto y recalibradas con el programa OxCal y la tabla radiocarbónica IntCal13.

\begin{tabular}{|c|c|c|c|c|c|c|}
\hline YACIMIENTO & MU. & ID. MU. & $\begin{array}{l}\text { FECHA } \\
\text { BP }\end{array}$ & $\begin{array}{c}68 \% \text { p cal } \\
\text { BC }\end{array}$ & $\begin{array}{c}95,4 \% \text { p cal } \\
\text { BC }\end{array}$ & REFERENCIA \\
\hline $\begin{array}{c}\text { Fondo } 8 \text { de } \\
\text { Vega de Santa } \\
\text { Lucía (fase B) }\end{array}$ & Carbón & UBAR-251 & $2660 \pm 50$ & $\begin{array}{c}68,2 \% \text { prob } \\
\\
892-877 \\
(10,1 \%) \\
846-796 \\
(58,1 \%)\end{array}$ & $916-776$ & $\begin{array}{c}\text { Murillo, 1994: } \\
126 \\
\text { (recalibrada) }\end{array}$ \\
\hline $\begin{array}{c}\text { El Carambolo } \\
\text { (UE 2116) }\end{array}$ & Carbón & Ua-24401 & $2770 \pm 50$ & $\begin{array}{c}68,2 \% \text { prob } \\
976-842\end{array}$ & $1029-814$ & $\begin{array}{c}\text { Fernández } \\
\text { Flores y } \\
\text { Rodríguez } \\
\text { Azogue, 2007: } \\
\text { fig. } 51 \\
\text { (recalibrada) }\end{array}$ \\
\hline $\begin{array}{l}\text { Jardín de Alá } \\
\text { (fondo J) }\end{array}$ & $\begin{array}{l}\text { Diente } \\
\text { humano }\end{array}$ & B225409 & $2710 \pm 40$ & 894-819 & $928-800$ & $\begin{array}{c}\text { Hunt y García } \\
\text { Rivero, 2017: } \\
\text { figs. 41-42 }\end{array}$ \\
\hline $\begin{array}{c}\text { Alarcos } \\
\text { (AL17-U18-3) }\end{array}$ & Carbón & Beta-473984 & $2700 \pm 30$ & $851-813$ & $905-806$ & $\begin{array}{l}\text { García Huerta, } \\
\text { 2019: cuadro } 1\end{array}$ \\
\hline $\begin{array}{c}\text { Alarcos } \\
\text { (AL17-U18-3-3) }\end{array}$ & Hueso & Beta-475572 & $2530 \pm 30$ & $791-750$ & $797-731$ & $\begin{array}{l}\text { García Huerta, } \\
\text { 2019: cuadro } 1\end{array}$ \\
\hline $\begin{array}{c}\text { Llanete de los } \\
\text { Moros (estrato III } \\
\text { A, R-1) }\end{array}$ & Carbón & UGRA-190 & $2930 \pm 110$ & $1415-852$ & $1427-823$ & $\begin{array}{l}\text { Mederos, 2017: } \\
\text { fig. } 15\end{array}$ \\
\hline
\end{tabular}

Fuente: Reimer, 2013 


\section{ESTUDIO DE LOS MATERIALES: LAS DECORACIONES}

Los fragmentos decorados de Calatrava la Vieja que se adscriben a este periodo son muy escasos, aunque relevantes ya que han permitido deducir contactos culturales con aquellas áreas geográficas en las que arraigó el horizonte decorativo en cuestión. Además, aportan una información cronológica fundamental, sobre todo para estos fragmentos que carecen de contexto.

\subsection{Cerámica de Cogotas I}

\subsubsection{Cerámica de boquique}

La cerámica de tipo Boquique de Calatrava la Vieja queda reducida a dos fragmentos (fig. 4:1-2). El primero de ellos es un galbo decorado con bandas de líneas impresas en zigzag y pequeñas líneas continuas que enmarcan la composición (fig. 4:1), mientras que el segundo, un recipiente de cuello troncocónico (fig. 4:2), muestra bajo el borde una línea incisa sobre la que se desarrolló una decoración impresa a base de motivos estilizados en "S". Por debajo de dicho motivo se ejecutó una decoración incisa de naturaleza geométrica, recurso que se recoge en el repertorio decorativo de este horizonte (Fernández Posse, 1982: 148, 156).

El motivo de pequeñas impresiones sobre una incisión continua se documenta en Mesa de Ablitas (Navarra) (Sesma, Bienes, Herce, Faro y Ramos, 2009: fig. 3:5), Higares (Mocejón, Toledo) (Abarquero 2005: fig. 45: 4, 21 y 23) o Castillo de Huete (Cuenca) (Martínez González y Martínez Navarrete 1988: fig. 1:3), constituyendo uno de los tipos decorativos más recurrentes en la tradición alfarera de Cogotas I (Blasco 1992: fig. 3:3; Abarquero 2005: figs. 22:11; 26:7 y 10; 32:1, 3,4; Ruiz Zapatero, 2007: fig. 4:g).

La técnica del boquique se ha vinculado unánimemente a Cogotas I, una cultura local del Bronce Medio-Final que se desarrolló en la Meseta Norte (Fernández Posse, 1982: 137; Pellicer, 1986: 440; 1987-88: 467; Blasco, 1992: 287; Blasco y Lucas, 2001: 224; Ruiz Zapatero, 2007: 40-41, fig. 4). La zona nuclear de esta cultura se ha ubicado en la cuenca del Duero y el sector septentrional de la Submeseta Sur (Abarquero, 2005: 68). Su fósil guía, la cerámica de tipo Boquique, se trata de una producción que en los últimos años ha ampliado su dispersión geográfica como consecuencia de las relaciones comerciales y culturales entre esta región y otras áreas peninsulares (Blasco, 1992: 287; García Huerta y Fernández Rodríguez, 2000: 51; Abarquero, 2005: 68 y ss).

Los hallazgos documentados en el Alto Guadiana han sido escasos, como los de Alarcos (García Huerta y Fernández Rodríguez, 2000: fig. 4), Plaza de los Moros (Malagón) (Blasco, 1986: 360), la Motilla del Azuer (Daimiel) (Nájera y Molina, 2004: 173-214) y Colonia Nueva o Los Amelgares (ambos en Miguelturra) (Zarzalejos, Esteban y Hevia, 2012: 17-18). Todos estos testimonios se hallaron fuera de contexto, salvo los de la Motilla del Azuer que se asocian a fechas radiocarbónicas que oscilan entre mediados del siglo XIII y finales del siglo XI cal. a.C. (Nájera y Molina, 2004: 205-206).

La importancia de este tipo de cerámica en el yacimiento de Calatrava la Vieja radica en la aproximación cronológica a la hora de valorar el momento fundacional del enclave, así como las relaciones establecidas con la Meseta Norte durante los primeros momentos del Bronce Final. Es probable que dichas relaciones se articularan en torno al 1200-1100 a. C., fecha que se ha propuesto para los fragmentos de Alarcos y la Plaza de los Moros (Morales, 2010: 97) y que sería extensible a los decorados con esta técnica en Calatrava la Vieja.

\subsubsection{Cerámica incisa e impresa de tradición Protocogotas}

La técnica incisa e impresa sólo aparece en un fragmento que está decorado en ambas superficies ribeteando el contorno del borde con motivos en zigzag (fig. 4:3). Bajo 
esta decoración, en la superficie externa, se ha conservado el inicio de una banda decorada a base de puntos impresos, detectándose una tonalidad rojiza que responde a la coloración de la pasta en las capas externas.

Los motivos incisos en zigzag de ambas superficies son típicos del horizonte de Protocogotas (Fernández Posse, 1982: figs. 2: 1,6,9,11,14; 3:2-5; Pellicer, 1987-88: fig. 9:1; Ruiz Zapatero, 2007: fig. 4c), fechado entre el 1400 y 1200 a. C. y en el que se desarrolló muy escasamente la técnica del boquique (Abarquero, 2005: 29-30). La relevancia de este hallazgo radica en su valor cronológico, ya que permite situar el límite superior del primer poblamiento de Calatrava en torno al 1200 a. C. La fecha estimada, correspondiente con el límite inferior del horizonte Protocogotas, parece ser la más prudente dada la posición secundaria del fragmento. Dicha consideración cronológica enlazaría con la documentación que ofrece el nivel III A del Llanete de los Moros, donde también se constata este motivo (Martín de la Cruz, 1987: fig. 37: 401, 402). La cronología absoluta de este estrato (Tabla 1), recientemente recalibrada por Mederos (2017: fig. 15), cubre un amplio intervalo que abarca del siglo XIV a finales del siglo IX cal. a. C. y que, en todo caso, incluiría la fecha estimada para el fragmento de Calatrava la Vieja.

\section{CONCLUSIONES Y VALORACIÓN FINAL: CALATRAVA LA VIEJA DURANTE EL BRONCE FINAL (ca. 1200-800 a. C.)}

Como varios autores han apuntado (Fernández Rodríguez, 2012: 42-43; Zarzalejos, Esteban y Hevia, 2012: 16), existe una evidente problemática en la periodización que atañe a la parte más meridional de la Meseta sur durante el periodo comprendido entre el Bronce Medio y el Ibérico Antiguo. Ello ha supuesto la adopción de términos que definen periodos coetáneos de los círculos culturales circundantes, como el área tartésica, el Sureste o la Meseta Norte. Atendiendo a los datos que han aportado otros yacimientos de la submeseta sur, se ha podido diferenciar un Bronce Final, una transición Bronce Final-Hierro I y un Hierro I u Orientalizante (Benítez de Lugo, Esteban y Hevia., 2004: 36-70), los cuales tienen su correspondencia respectiva con el Bronce Final, Hierro I Inicial y Hierro I Avanzado (Morales, 2010: 96-100). De estas tres etapas, es el Bronce Final el que presenta una mayor problemática en cuando a su delimitación cronológica y definición cultural o tipológica. Así, a día de hoy no se ha constatado ningún nivel arqueológico del Bronce Final en el Alto Guadiana, salvo la Fase V de la Motilla del Azuer en la que se documentaron cerámicas de Cogotas I asociadas a la data radiocarbónica ya citada. Lamentablemente, la mayor parte de la documentación arqueológica de este periodo se halla en superficie o fuera de contexto, incluidos los materiales de Calatrava la Vieja. Por tanto, una aproximación a esta etapa, dada la naturaleza de la información disponible, sólo puede realizarse a través de los estudios tipológicos, teniendo como referencia aquellos materiales que se encuentran en posición primaria, especialmente los que aparecen relacionados con dataciones absolutas.

A partir de la documentación arqueológica disponible, el inicio del Bronce Final en la Meseta suroriental se ha caracterizado por la confluencia de diversas corrientes culturales en un contexto de cambio en el patrón de asentamiento, quizás como respuesta a una nueva dinámica socioeconómica motivada por este nuevo impacto cultural (Morales, 2010: 93-95). En un primer momento destacan los contactos con la cultura de Cogotas I y el mundo atlántico, estos últimos materializados en el depósito de armas de Puertollano (Fernández Rodríguez y Rodríguez de la Esperanza, 2002), el hacha de talón de El Embocadero (Ciudad, 1986: 25-26) o el brazalete de La Alcudia (Almagro-Gorbea, 1977: fig. 14) entre otros. Por su parte, las relaciones con la Meseta Norte quedan constatada a través de todas aquellas cerámicas de Cogotas I (Fernández Rodríguez, 2012: 43; Zarzalejos, Esteban y Hevia, 2012: 15-40), como los ejemplares analizados de Calatrava la Vieja, que deben 
responder a unas relaciones de tipo comercial (Abarquero, 2005: 107). Estas conexiones con el Alto Guadiana coincidirán con los últimos pasos de Cogotas I, fechados en torno a los siglos X-IX a. C. (Ruiz Zapatero y Lorrio, 1988: 257-258; Blasco, 1992: 284, 286; Blasco y Lucas, 2001: 222; Abarquero, 2005: 67; Ruiz Zapatero, 2007: 40), aunque Mederos (2012: 75-107) marcó este ocaso entre el 1225 y el 1150 a. C. Sin embargo, los ejemplares de Protogocotas de Calatrava permiten retrotraer dichos contactos, como mínimo, al 1200 a. C. Dicha consideración cronológica permite situar provisionalmente el límite superior de Calatrava la Vieja en el Bronce Final II en fechas calibradas o en los inicios del Bronce Final IC en fechas sin calibrar (Mederos, 1997: tablas 17 y 18; 2017: 119).

La presencia de cerámicas de tipo Boquique en la Meseta suroriental pone en evidencia la existencia de unas rutas comerciales, jalonadas en un eje Norte-Sur, que atravesarían este espacio para alcanzar las zonas más meridionales, solventado con ello el problema de la llegada de estas cerámicas a la Andalucía Oriental sin necesidad de recurrir a la Vía de la Plata y el Valle del Guadalquivir como única vía de penetración (Pellicer, 1986: 441). De hecho, en los últimos años se ha ido completando ese aparente vacío en la Meseta sur con nuevos testimonios de cerámica cogoteña (Zarzalejos, Esteban y Hevia, 2012: 17-19). Sin embargo, y dado el estado actual de la investigación, sería difícil conocer la organización y control de este comercio de productos de origen meseteño en el Alto Guadiana.

El núcleo de población del Bronce Final, situado en Calatrava la Vieja en torno al 1200 a. C., queda lejos de ser definido con claridad, no sólo por las limitaciones que suponen los hallazgos estudiados sino por las características del patrón de poblamiento durante este periodo. El sustrato local sería lo más difícil de definir ya que se desconoce la cultura material que lo representó en estos momentos, aunque sería lógico pensar en unas formas continuadoras de la tradición del Bronce Medio si se acepta la hipótesis que aboga por una perduración de los grupos del Bronce Pleno durante el Bronce Final (Almagro Gorbea, 1999: 29; Zarzalejos, Esteban y Hevia, 2012: 36-37). En función de esto y en el hecho de que, salvo Alarcos (Juan, Fernández y Caballero, 1994: 145-147; García Huerta y Fernández Rodríguez, 2000: 64), la mayor parte de los poblados íberos de la Oretania septentrional presentan unos niveles de fundación que remiten al periodo transicional Bronce FinalHierro I sin detectarse una fase del Bronce Pleno (Benítez de Lugo, Esteban y Hevia, 2004: 53), podrían incluirse los fragmentos de Calatrava emparentados con la cultura material del Bronce de La Mancha como la representación de la tradición vascular de las poblaciones locales de estos momentos. Tal es el caso de los recipientes con cuello de perfil en "S", los vasos bicónicos de pequeño tamaño (fig. 4:14) o los recipientes cerrados con mamelones (fig. 4:15) con paralelos en los yacimientos manchegos del Bronce Medio (Nieto y Sánchez Meseguer, 1980: figs. 49: abajo izquierda, 50: abajo; García Pérez, 1987: figs. 15, 18: arriba derecha).

Por tanto, el horizonte material con filiación en las tradiciones del Bronce Medio que se ha documentado en Calatrava la Vieja podría reflejar la perduración del bagaje cultural de las poblaciones locales que, durante el Bronce Final, experimentaron un cambio en el patrón de asentamiento por causas aún desconocidas. Esta hipótesis implica un sustrato eminentemente local para los poblados del Bronce Final del Alto Guadiana, sustrato que, no obstante, experimentaría cambios cultuales como consecuencia de la red de contactos establecida durante ese momento. Dicha evolución cultural se vería reflejada en la cultura material, ya que es muy probable que algunas de las formas o decoraciones típicas de otras áreas peninsulares se elaboraran en el propio poblado de Calatrava la Vieja, aspectos que esperamos aclarar con los futuros análisis arqueométricos.

En las postrimerías del Bronce Final, cuando las influencias de Cogotas I languidecen, se dejarían notar los contactos con el Suroeste, situación fielmente reflejada en la Meseta 
suroriental a través de algunos elementos materiales como la cerámica estilo Carambolo (García Huerta y Fernández Rodríguez, 2000: fig. 5:2). En estos momentos, en los que el Suroeste ya estaba inserto en el ambiente cronológico y cultural de la Primera Edad del Hierro, se fecharían todas aquellas formas de Calatrava con paralelos en el valle del Guadalquivir, como las cazuelas A.I.a, A.I.b, los vasos bicónicos del tipo A.I.f y el soporte de carrete. Las relaciones con el Suroeste se exacerbarán durante la transición Bronce Final-Hierro I y la Primera Edad del Hierro, periodo para el que ya se cuenta con una documentación arqueológica más fiable. La fecha de mediados del siglo VIII a. C. que se ha propuesto para algunas de estas formas indicaría supondría su perduración durante la etapa transicional Bronce Final-Hierro I como fue habitual en los contextos estratificados del Alto Guadiana.

Las relaciones entre el Suroeste y la Meseta Sur fueron tan intensas que se ha llegado incluso a plantear la incorporación de la Meseta suroriental en el área de la cultura tartésica durante el siglo VII a. C. (Ruiz y Molinos, 2008: 67) o la explotación metalífera de La Bienvenida por los tartesios (Zarzalejos, Fernández, Esteban y Hevia, 2015: 47). Dichas valoraciones se han reafirmado recientemente a partir de la exhumación de un edificio orientalizante con paralelos en el mundo tartésico (Zarzalejos, Esteban y Hevia, 2017).

Todo lo aquí expuesto autoriza con argumentos sólidos la inclusión de Calatrava la Vieja entre aquellos yacimientos del Alto Guadiana con un horizonte preibérico cuyos orígenes se sitúan, como mínimo, en el Bronce Final y en fechas en torno al 1200 a.C. Así lo reflejan los materiales analizados que evidencian una amplia red de contactos que relacionaron a Calatrava la Vieja con la Meseta Norte o el Suroeste durante este periodo. Esta circunstancia vendría favorecida por la posición central de la Meseta Sur, sobre todo si se tiene en cuenta la ubicación de Calatrava en una pequeña elevación amesetada que domina en un amplio territorio de llanos.

Los contactos con el Bajo Guadalquivir probablemente se vehicularon a través de la posterior Vía de la Plata, la cual atraviesa la Meseta en un eje Norte-Sur, aunque hay autores que ya valoraron la posición estratégica de Calatrava la Vieja en aquellas rutas que unían La Mancha con el Guadalquivir Medio (Martín de la Cruz, 1987: 26, 200). Dicha conexión explicaría los paralelismos que se han apuntado entre los materiales de Calatrava la Vieja y los de Vega de Santa Lucía, La Saetilla o El Llanete de los Moros. De hecho, en época medieval el Llanete de los Moros y Calatrava la Vieja fueron dos enclaves destacados en la vía que conectaba Toledo con Córdoba (Martín de la Cruz, 1987: 26).

Por otro lado, la variedad y calidad de algunas formas constatadas en Calatrava la Vieja revela la existencia de una sociedad compleja en la que, muy probablemente, existió una vajilla de uso restringido que iría asociada a nuevas costumbres en la forma de consumir los alimentos. Las piezas adquiridas por vía comercial tendrían un valor añadido, por lo que es muy probable que su empleo se reservara para aquellos momentos en los que los individuos visualizaran su posición social. Aunque la estructura social y económica de las sociedades del Bronce Final son muy desconocidas en el Alto Guadiana, el acceso a productos de calidad a través del comercio, como las cerámicas de Cogotas I, sugiere una intensificación de las desigualdades y, con ello, una mayor jerarquización social.

En definitiva, Calatrava la Vieja ha contribuido con sus hallazgos a la definición tipológica de una de las etapas peor conocidas de la Meseta Suroriental. Aún con ello, el Bronce Final sigue sumido en una evidente oscuridad que se pretende ir aclarando con futuros trabajos arqueológicos en los que se espera constatar niveles de esta época. 
Figura 3. Yacimientos citados

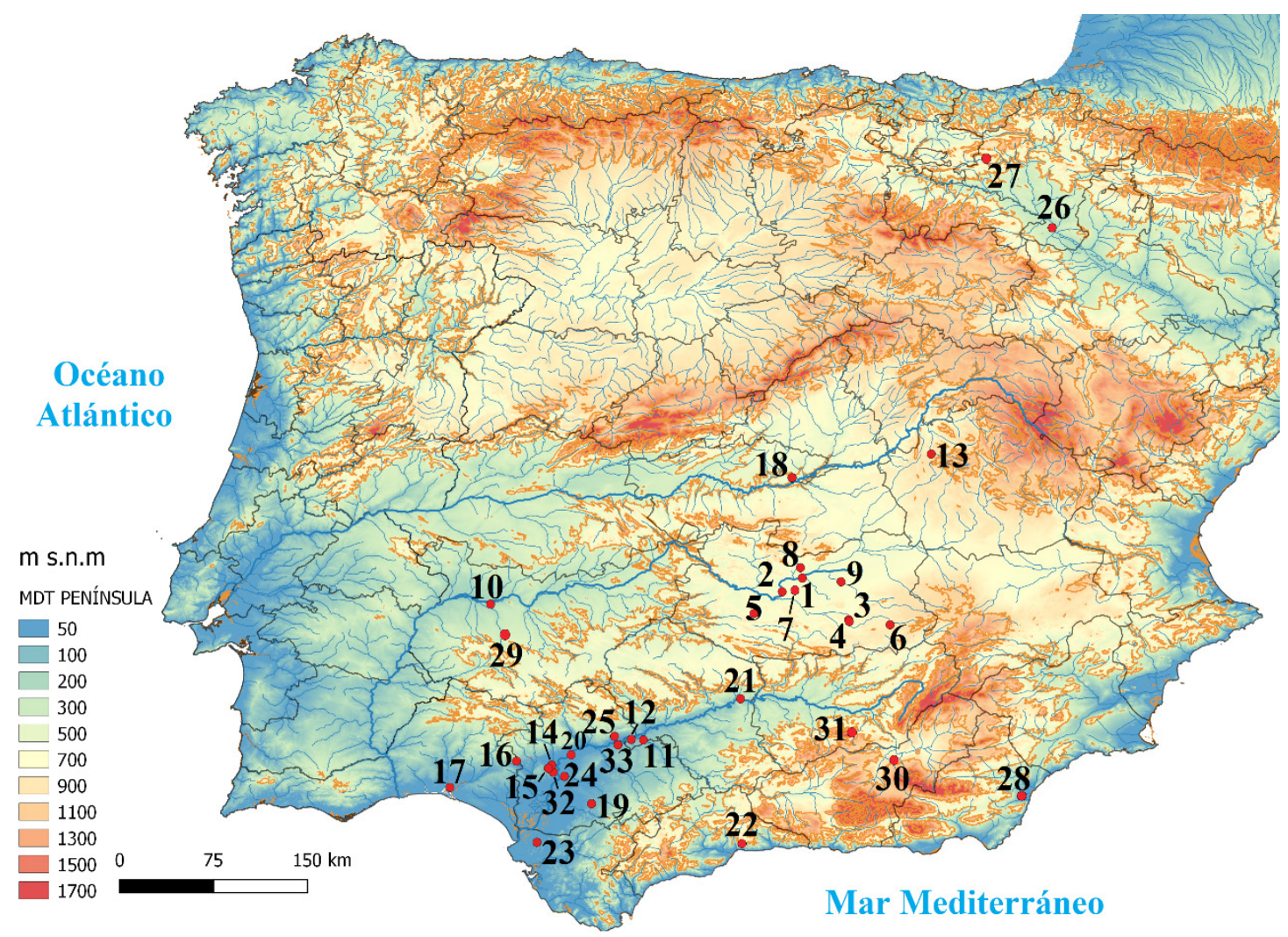

Fuente: elaboración propia. 1. Calatrava la Vieja (Carrión de Calatrava, Ciudad Real); 2. Alarcos (Poblete, Ciudad Real); 3. Casa de Rana (Valdepeñas, Ciudad Real); 4. Cerro de las Cabezas (Valdepeñas, Ciudad Real); 5. La Bienvenida-Sisapo (Almodóvar del Campo, Ciudad Real); 6. La Pizarrilla (Cózar, Ciudad Real); 7. Colonia Nueva y Los Amelgares (Miguelturra, Ciudad Real); 8. Plaza de los Moros (Malagón, Ciudad Real); 9. Motilla del Azuer (Daimiel, Ciudad Real); 10. Los Concejiles (Lobón, Badajoz); 11. Vega de Santa Lucía (Palma del Río, Córdoba); 12. La Saetilla (Palma del Río, Córdoba); 13. Castillo de Huete (Huete, Cuenca); 14. El Carambolo (Camas, Sevilla); 15. Cerro de la Cabeza (Valencina de la Concepción, Sevilla); 16. Peñalosa (Escacena del Campo, Huelva); 17. Cabezo de San Pedro (ciudad de Huelva, Huelva); 18. Higares (Mocejón, Toledo); 19. Cerro del Casar (El Coronil, Sevilla); 20. Puerto del Barco (Brenes, Sevilla); 21. Llanete de los Moros (Montoro, Córdoba); 22. San Pablo (Málaga); 23. Mesas de Asta (Jerez de la Frontera, Cádiz); 24. Universidad Laboral (Alcalá de Guadaira, Sevilla); 25. Mesa de Setefilla (Lora del Río, Sevilla); 26. Mesa de Ablitas (Ablitas, Navarra); 27. Las Roturas II (Los Arcos, Navarra); 28. Fuente Álamo (Cuevas de Almanzora, Almería); 29. Castillo de Alange (Alange, Badajoz); 30. Cuesta del Negro (Purullena, Granada); 31. El Canjorro (Jaén); 32. Jardín de Alá (Salteras, Sevilla); 33. Cuesta de los Cipreses (Osuna, Sevilla) 
Figura 4. Formas del Bronce Final

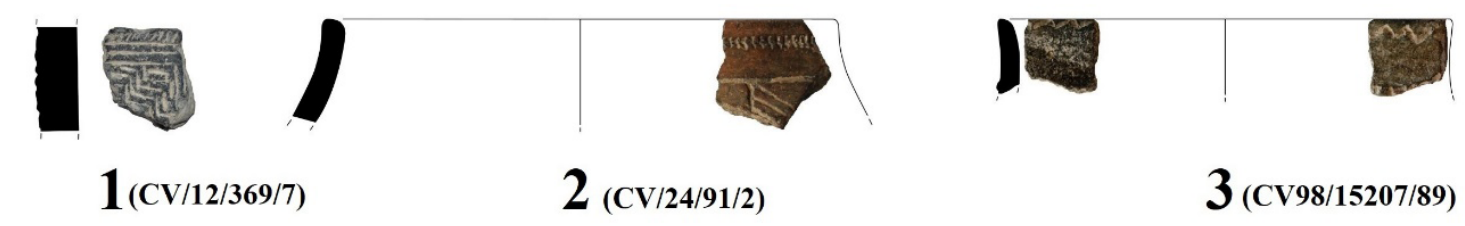

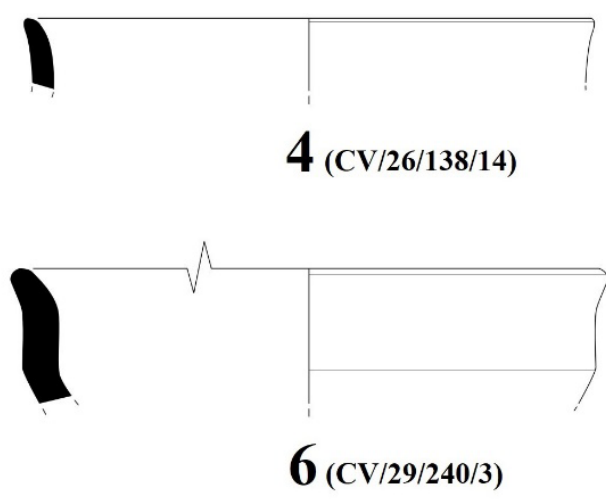

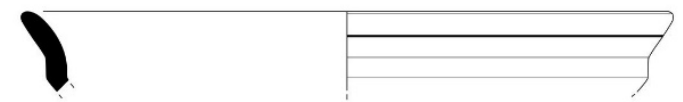

$8_{(\mathrm{CV} / 17 / 8 / 18)}$

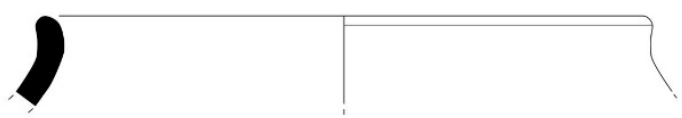

$10(\mathrm{CV} 09 / 17 / 41 / 41)$

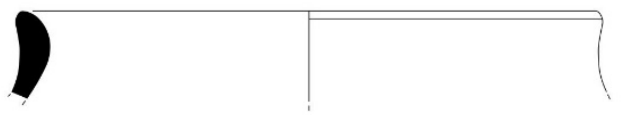

$12_{(\mathrm{CV} / 17 / 184 / 13)}$

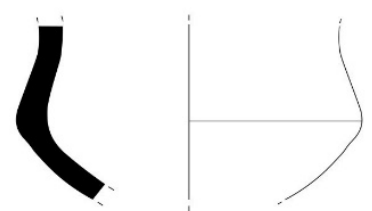

$14_{(\mathrm{CV} / 26 / 582 / 2)}$

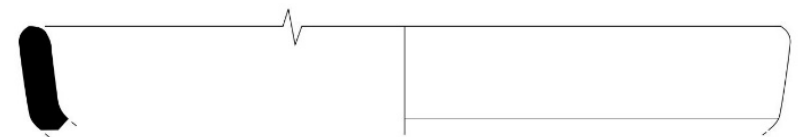

5 (CV01/24/51/4)

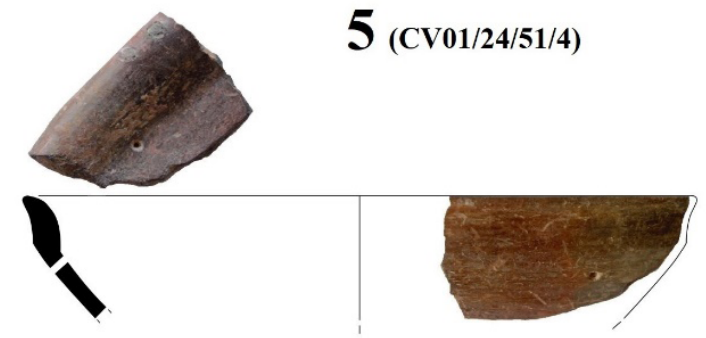

$7_{\text {(CV84/C-5/82/4254) }}$

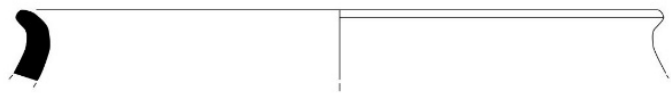

$9_{\text {(CV97/15/206/23) }}$

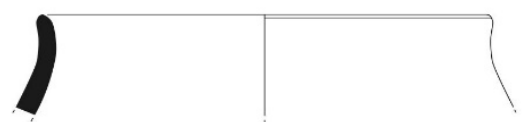

$11_{(\mathrm{CV} 84 / \mathrm{C}-5 / 104 / 4200)}$

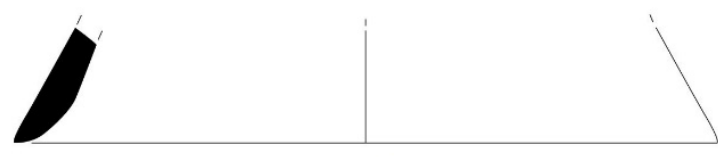

13 (CV/26/446/55)
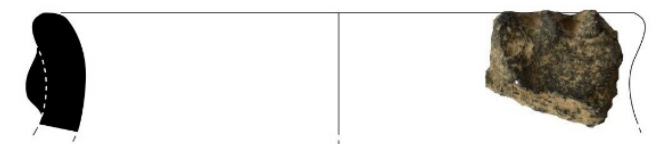

$155_{(\mathrm{CV} / 12 / 366 / 1)}$

1. Galbo con decoración de boquique; 2. Recipiente con cuello troncocónico; 3-4. Vasos cerrados de borde apuntado; 5. Cazuela de borde recto y perfil trapezoidal; 6-7. Cazuelas del tipo A.I.a; 8. Cazuela A.I.b; 9-12. Vasos bicónicos del tipo A.I.f; 13. Soporte de carrete; 14-15. Cerámicas de tradición del Bronce Medio. 


\section{BIBLIOGRAFÍA}

Abarquero, F. J. (2005): Cogotas I. La difusión de un tipo cerámico durante la Edad del Bronce, Valladolid.

Almagro-Gorbea, M., (1977): El Bronce Final y el Periodo Orientalizante en Extremadura (=Bibliotheca Praehistorica Hispana, XIV), Madrid.

- (1999): "Los íberos en Castilla-La Mancha", en I Jornadas de Arqueología Ibérica en Castilla-La Mancha, pp. 25-48.

Belén, M. (2001): "La cremación en las necrópolis tartésicas", en Arqueología funeraria. Las necrópolis de incineración. Cuenca, pp. 37-78.

Benítez de Lugo, L., Esteban, G. y Hevia, P. (2004): Protohistoria y Antigüedad en la provincia de Ciudad Real, Ciudad Real.

Blanco, J. F., Hervás, M. A. y Retuerce, M. (2012): "Una primera aproximación arqueológica al oppidum oretano de Calatrava la Vieja (Carrión de Calatrava, Ciudad Real)", Real Acadèmia de Cultura Valenciana. Sección de estudios ibéricos "D. Fletcher Valls". Estudios de lenguas y epigrafía antiguas, 12, pp. 85-150

Blasco, C. (1992), "Etnogénesis de la Meseta Sur", Paleoetnología de la Península Ibérica, Complutum, 2-3, pp. 281-297

Blasco, C. y Lucas, M. R. (2001): "Problemática del Bronce Final en la Meseta", Spal, 10, pp. 221-233.

Blázquez J. M., Ruiz Mata, D., Remesal, J., Ramírez, J. L. y Clauss, K. (1979): Excavaciones en el Cabezo de San Pedro (Huelva). Campaña de 1977 (=Excavaciones Arqueológicas en España, 102), Madrid.

Brandherm, D. y Krueger, M. (2017): "Primeras determinaciones radiocarbónicas de la necrópolis de Setefilla (Lora del Río) y el inicio del periodo orientalizante en Andalucía occidental", Trabajos de Prehistoria 74 (2), pp. 296-318.

Carriazo, J. de M. (1973): Tartessos y El Carambolo. Investigaciones arqueológicas sobre la Protohistoria de la Baja Andalucía. Madrid.

Casado, M. (2015): La cerámica con decoración geométrica del Carambolo (=Spal monografías, 21), Sevilla.

Celestino, S. y Rodríguez González, E. (2017): "De lo invisible a lo visible. La transición entre el Bronce final y la Primera Edad del Hierro en el valle medio del Guadiana", en Territorios comparados: Los valles del Guadalquivir, el Tajo y el Guadiana en época tartésica. Reunión científica, Mérida (Badajoz, España) 3-4 diciembre 2015. (=Anejos de Archivo Español de Arqueología, 80), Mérida, pp. 183-212.

Ciudad, A. (1986): Poblamiento y culturas en la Prehistoria, Historia de Ciudad Real, Ciudad Real.

Escacena, J. L. (1995): "La etapa precolonial de Tartessos. Reflexiones sobre el "Bronce" que nunca existió, en Tartessos, 25 años después 1968-1993, Jerez de la Frontera, pp. 179-214.

Esteban, G., Hevia, P., Pérez J. J. y Vélez, J. (2003): "La transición del Bronce Final a la Primera Edad del Hierro en el Cerro de las Cabezas (Valdepeñas, Ciudad Real)", Cuadernos de Estudios Manchegos, 25-26, pp. 11-42.

Fernández Flores, F. y Rodríguez Azogue, A. (2007): Tartessos desvelado. La colonización fenicia del Suroeste peninsular y el origen y ocaso de Tartessos, Sevilla.

Fernández Gómez, F. y Buero, M. S. (2010): "El problema del origen y cronología del Bronce Final-Orientalizante en Andalucía Occidental a través del fondo de cabaña de la Universidad Laboral de Sevilla", Temas de Estética y Arte, 24, pp. 69-110.

Fernández Ochoa, C., Zarzalejos, M., Hevia, P. y Esteban, G. (1994): Sisapo I. Excavaciones arqueológicas en "La Bienvenida", Almodóvar del Campo (Ciudad Real), Toledo. 
Fernández Posse, M. D. (1982): "Consideraciones sobre la técnica de boquique", Trabajos de Prehistoria, 39, pp. 137-159

Fernández Rodríguez, M. (2001): “La necrópolis del sector IV de Alarcos (Ciudad Real)", en Arqueología funeraria: las necrópolis de incineración, Cuenca, pp. 259-284

Fernández Rodríguez, M. y Rodríguez de la Esperanza, M. J. (2002): "Los depósitos de armas en el Bronce Final: Un nuevo hallazgo en Puertollano (Ciudad Real)", Trabajos de Prehistoria 59 (2), pp. 113-133.

Fernández Rodríguez, M. (2012): "Apuntes sobre el Bronce Final y la Primera Edad del Hierro en Alarcos (Ciudad Real)", en Siderum Ana II. El río Guadiana en el Bronce Final (=Anejos de Archivo Español de Arqueología, 62), Mérida, pp. 41-64.

Ferrer, E., Ruiz, J. I y García Fernández, F. J. (2017): "Nuevos datos sobre el Bronce Final en Osuna", en Territorios comparados: Los valles del Guadalquivir, el Tajo y el Guadiana en época tartésica. Reunión científica, Mérida (Badajoz, España) 3-4 diciembre 2015. (=Anejos de Archivo Español de Arqueología, 80), Mérida, pp. 79-119

García Alfonso, E. (2007): A la orilla de Tartessos. Indígenas y fenicios en las tierras malagueñas. Siglos XI-VI a. C, Málaga.

García Huerta, M R. y Fernández Rodríguez, M. (2000): "La génesis del mundo ibérico en la Submeseta Sur: El tránsito del Bronce Final- I Edad del Hierro en Alarcos", Cuadernos de Prehistoria y Arqueología de la Universidad Autónoma de Madrid, 26, pp. 47-68.

García Huerta, M. R., Morales, F. J., Vélez, J., Soria, L. y Rodríguez González, D. (2006): "Hornos de pan en la Oretania septentrional", Trabajos de Prehistoria, 63 (1), pp. 157166.

García Huerta, M. R., Morales, F. J. (2017): "El poblado de Alarcos (Ciudad Real) en los inicios del I milenio a. C.: estructuras y materiales cerámicos", Trabajos de Prehistoria, 74 (1), pp. 108-126.

García Huerta, M. R. (2019): "Las cerámicas pintadas postcocción de la Meseta Sur: el ejemplo de Alarcos (Ciudad Real)", en Las cerámicas a mano pintadas postcocción de la península ibérica durante la transición entre el Bronce Final y la I Edad del Hierro. (=Mytra, 4), Mérida, pp. 39-74.

García Pérez, T. (1987): "La motilla de los Romeros. Alcázar de San Juan (Ciudad Real)", Oretum, 3, pp. 111-165.

García Sanz, C. y Fernández Jurado, J. (2000): "Peñalosa (Escacena del Campo, Huelva). Un poblado de cabañas del Bronce Final”, Huelva Arqueológica 16, pp. 5-87.

González de Canales, F.; Serrano Pichardo, L. y Lompart, J. (2010): "El inicio de la Edad del Hierro en el Suroeste de la península ibérica, las navegaciones precoloniales y cuestiones en torno a las cerámicas de Huelva", en IV Encuentro de Arqueología del Suroeste. Aracena (Huelva), 27-29 de noviembre de 2009, Publicación digital, pp. 648-697.

Hunt M. A. y García Rivero, D. (2017): "El asentamiento protohistórico de Jardín de Alá (Salteras, Sevilla)", en Territorios comparados: Los valles del Guadalquivir, el Tajo y el Guadiana en época tartésica. Reunión científica, Mérida (Badajoz, España) 3-4 diciembre 2015. (=Anejos de Archivo Español de Arqueología, 80), Mérida, pp. 47-77.

Juan, A. de, Fernández Rodríguez, M. y Caballero, A. (1994): "El yacimiento Íbero-Medieval de Alarcos", en Jornadas de Arqueología en Ciudad Real en la Universidad Autónoma de Madrid, Toledo, pp. 143-165.

López Roa, C. (1977): "La cerámica con decoración bruñida en el Suroeste peninsular", Trabajos de Prehistoria, 34, pp. 341-370.

Martín de la Cruz, J. C. (1987): El Llanete de los Moros. Montoro, Córdoba (=Excavaciones Arqueológicas en España, 151), Madrid. 
Martínez González, J. Ma y Martínez Navarrete, M. I. (1988): "La ocupación del Final de la Edad del Bronce en el Castillo de Huete (Cuenca), I Congreso de Historia de CastillaLa Mancha-Tomo III: Pueblos y culturas prehistóricas y protohistóricas (2), Toledo, pp. 217-227.

Mederos, A. (1997): "Nueva cronología del Bronce Final en el Occidente de Europa", Complutum, 8, pp. 73-96.

- (2012): "El final de Cogotas I y los inicios de la Edad del Hierro en el centro de la Península Ibérica (1200-800 AC)", en El primer milenio a.C. en la Meseta central. De la longhouse al oppidum (Madrid, 2008), Madrid, pp. 73-107.

- (2017): “La cronología de la cerámica pintada monocroma roja tipo Carambolo del Bronce

Final IIC-III e inicios de la Edad del Hierro del Suroeste de la Península Ibérica (1150-

825 a.C.)", en Memento dierum antiquorum... Festschrift für Majolie Lenerz-de Wilde zum 70. Geburstag. Hagen, pp. 105-125.

Miguel, P. (2014): "Nuevos testimonios de cerámica griega en el yacimiento de Calatrava la Vieja (Carrión de Calatrava, Ciudad Real)", Sautuola, 19, pp. 191-201.

- (2017): "Hacia la configuración del oppidum oretano: Calatrava la Vieja en la transición Bronce Final-Hierro I", Cuadernos de Prehistoria y Arqueología de la Universidad Autónoma de Madrid, 43, pp. 33-45.

- (2019): "Calatrava la Vieja durante la Primera Edad del Hierro (c. fin. S. VIII-550 a.C.)", Spal 28 (1), pp. 79-96.

Morales, F. J. (2010): El poblamiento de la época íbera en la Provincia de Ciudad Real, Cuenca.

Murillo, J. F. (1994): La cultura tartésica en el Guadalquivir Medio (=Ariadna, 13-14).

Nájera, T. y Molina, F. (2004): "Las Motillas. Un modelo de asentamiento con fortificación central en la llanura de La Mancha", en La Península Ibérica en el II milenio a. C.: Poblados y fortificaciones, Cuenca, pp. 173-214.

Nieto, G. y Sánchez Meseguer, J. (1980): El Cerro de la Encantada (Ciudad Real) (=Excavaciones Arqueológicas en España, 113), Madrid.

Pellicer, M. (1986): "El Bronce Reciente y los inicios de del Hierro en Andalucía oriental", Habis, 18-19, pp. 433-475.

- (1987-1988): "Las cerámicas a mano del Bronce Reciente y del Orientalizante en Andalucía Occidental", Habis, 18-19, p. 461-483

Pérez Avilés, J. J. (1985): "Estudio arqueológico del Campo de Montiel”, Oretum 1, pp. 175237

Pérez Avilés, J. J. y Vélez, J. (1994): "El yacimiento protohistórico del Cerro de «las Cabezas», Valdepeñas, Ciudad Real”, en Jornadas de Arqueología en Ciudad Real en la Universidad Autónoma de Madrid, Toledo, pp. 133-141.

- (1996): "Estudio sobre la Protohistoria de Valdepeñas y su comarca", Cuadernos de Estudios Manchegos, 22, pp. 9-37.

Reimer, P. J.; E. Bard, E.; Bayliss, A.; Beck, J. W.; Blackwell, P. G.; Bronk Ramsey, C.; Buck, C. E.; Cheng, H.; Edwars, R. L.; Friedrich, M.; Grootes, P. M.; Guilderson, T. P.; Haflidason, H.; Hajdas, I.; Hatt, C.; Heaton, T. J.; Hoffmann, D. L.; Hogg, A. G.; Huchen, K. A.; Kaiser, K. F.; Kromer, B.; Manning, S. W.; Niu, M.; Reimer, R. W.; Richards, D. A.; Scott, E. M.; Southon, J. R.; Staff, R. A.; Turney, C. S. M. y Van der Plicht, J. (2013): "INTCAL13 and marine INTCAL13 radiocarbon age calibration curves 0-50,000 years Cal BP.", Radiocarbon, 55 (4), pp. 1869-1887.

Retuerce M. (1994): "Calatrava la Vieja. Diez años de investigación arqueológica”, en Jornadas de Arqueología en Ciudad Real en la Universidad Autónoma de Madrid, Toledo, pp. 212-241. 
Retuerce, M. y Hervás, M. A. (2004): "Excavaciones arqueológicas en Calatrava la Vieja", en Investigaciones arqueológicas en Castilla-La Mancha 1996-2002, Salamanca, pp. 381-394.

Rodríguez González, E. (2018): El poblamiento del Medio Guadiana durante la I Edad del Hierro (=Bibliotheca Praestorica Hispana, 34), Madrid.

Ruiz, A. y Molinos, M. (2008): "Las fuentes del Guadalquivir. Límites y fronteras para el norte de la Bastetania", en I Congreso Internacional de Arqueología Ibérica Bastetana (Serie Varia, 9), Madrid, pp. 51-72.

Ruiz Mata, D., Blázquez, J. M. y Martín de la Cruz, J. C. (1981): "Excavaciones en el Cabezo de San Pedro (Huelva). Campaña de 1978", Huelva Arqueológica, 5, pp. 149-316.

Ruiz Mata, D. (1984-1985): "Puntualizaciones sobre la cerámica pintada tartésica del Bronce Final-Estilo carambolo o Guadalquivir l", Cuadernos de Prehistoria y Arqueología de la Universidad Autónoma de Madrid, 11-12, pp. 225-243.

-- (1995): "Las cerámicas del Bronce Final. Un soporte tipológico para delimitar el tiempo y el espacio tartésico", Tartessos, 25 años después 1968-1993, Jerez de la Frontera, pp. 265-313.

-- (2014): "La cerámica pintada geométrica tartésica", La pieza del mes. 27 de septiembre de 2014, pp. 1-11.

Ruiz Zapatero, G. (2007): "Antes del Hierro. Cultura y sociedad en el centro de la meseta (ca. 1200-500 a. C.)", Zona Arqueológica, 10 (1), pp. 36-63.

Ruiz Zapatero, G. y Lorrio, A. (1988): "Elementos e influjos de "Campos de Urnas" en la Meseta Sudoriental", I Congreso de Historia de Castilla-La Mancha-Tomo III: Pueblos y culturas prehistóricas y protohistóricas (2), Toledo, pp. 257-267

Sesma, J., Bienes, J. J., Herce, A., Faro, J. A. y Ramos, M. (2009): "La cerámica de estilo Cogotas I y los inicios culturales en las postrimerías de la Edad del Bronce en Navarra", Cuadernos de Arqueología de la Universidad de Navarra, 17, pp. 39-83

Torres, M. (1996): "La cronología de los túmulos A y B de Setefilla. El origen del rito de la cremación en la cultura tartésica", Complutum, 7, pp. 147-162

- (2001): "Cerámica a mano con decoración de botones de bronce: una aportación al estudio de la alfarería tartésica del Bronce Final", Spal 10, pp. 275-281.

- (2002): Tartessos (=Bibliotheca Archaeologica Hispana, XIV, Studia Hispano-phoenica, 1), Madrid

- (2008): "The Chronology of the Late Bronze Age in Western Iberia and the beginning of the Phoenician colonization in the Western Mediterranean". A new Dawn for the Dark Age? Shifting Paradigms in Mediterranean Iron Age Chronology. (BAR International Series, 1871). Oxford, pp. 135-147.

- (2016): "Algunas consideraciones cronológicas sobre el yacimiento tartésico de El Carambolo", Cadernos do Museu da Lucerna, II. Atas da Mesa Redonda Turdetânea e turdetanos, Castro Verde, pp. 78-96.

Vélez, J. y Pérez Avilés, J. J. (1987): “El yacimiento protohistórico del Cerro de las Cabezas (Valdepeñas. Ciudad Real)", Oretum 3, pp. 167-196.

- (1999): "Oretanos en la Meseta Sur. El yacimiento ibérico del Cerro de las Cabezas", Revista de Arqueología, 213, pp. 46-55.

Vilaça, R., Jiménez Ávila J. y Galán, E. (2012): "El poblado de los Concejiles (Lobón, Badajoz)", en Siderum Ana II. El río Guadiana en el Bronce Final (=Anejos de Archivo Español de Arqueología, 62), Mérida, pp. 125-165.

Zarzalejos M., Fernández Ochoa, C. y Hevia, P. (2004): "El proyecto Sisapo-La Bienvenida (Almodóvar del Campo, Ciudad Real). Balance de los trabajos más recientes y nuevas perspectivas de la investigación", en Investigaciones arqueológicas en Castilla-La 
Mancha, Salamanca, pp. 163-181.

Zarzalejos, M. y López Precioso, F. J. (2005): "Apuntes para una caracterización de los procesos orientalizantes en la Meseta Sur", en El periodo Orientalizante. Actas del III Simposio Internacional de Arqueología de Mérida: Protohistoria del Mediterráneo Occidental (=Anejos de Archivo Español de Arqueología, 35), vol. 2, Mérida, pp. 809-84. Zarzalejos, M., Esteban, G. y Hevia, P. (2012): “El Bronce Final en el Alto Guadiana. Viejos y nuevos datos para una lectura histórica", en Siderum Ana II. El río Guadiana en el Bronce Final (=Anejos de Archivo Español de Arqueología, 62), Mérida, pp. 15-40.

Zarzalejos, M., Fernández Ochoa, C., Esteban, G. y Hevia, P. (2015): "Contribuciones al conocimiento del territorio de Sisapo (La Bienvenida, Almodóvar del Campo) en la Antigüedad: una visión arqueológica", en I Congreso Nacional. Ciudad Real y su provincia, Ciudad Real, tomo I, pp. 39-56.

Zarzalejos, M., Esteban, G. y Hevia, P. (2017): "El Alto Guadiana entre los siglos VIII y VI a. C. Novedades estratigráficas en el área 4 de Sisapo-La Bienvenida (almodóvar del Campo-Ciudad Real)", en Siderum Ana III. El río Guadiana y Tartessos, Mérida, pp. 39-67. 